\title{
Gaining a Competitive Advantage through Sustainability Strategy: Managerial Applications for the Mining Sector
}

\author{
Yuliia Lazarenko ${ }^{1, *}$, Olga Garafonova ${ }^{1}$, Vyktoriia Marhasova², and Svetlana Grigashkina ${ }^{3}$ \\ ${ }^{1}$ Kyiv National Economic University named after Vadym Hetman, Management Department, 03057, \\ 54/1 Pr. Peremogy, Kyiv, Ukraine \\ ${ }^{2}$ Chernihiv Polytechnic National University, Department of Theoretical and Applied Economics, \\ 14035, Chernihiv, Shevchenko str.,95, Ukraine \\ ${ }^{3}$ T.F. Gorbachev Kuzbass State Technical University, 65000028 Vesennya st., Kemerovo, Russia
}

\begin{abstract}
In today's business environment, sustainability is becoming an increasing issue for decision-makers, because it is concerned with sustainable development in terms of environmental, economic, and social dimensions. In view of this, mining companies worldwide understand the significance of the strategic approach to sustainability management. However, the formulation and implementation of the appropriate sustainability strategy in order to gain a competitive advantage of sustainability initiatives may be a challenging task for organizations. The paper aims to clarify the concept of sustainable competitiveness in the context of the mining industry and define the main focus areas of strategic sustainability management at the firm level. Based on a literature review a conceptual framework for strategic sustainability management of mining companies is presented, which includes key drivers and organizational factors that should be taken into account to embed efficiently the sustainability strategies into the business practice. From a management viewpoint, the presented framework can be conceptualized at the firm level as a business model which is oriented towards the achievement of competitive advantage, long-term value creation, and enhancing corporate sustainability performance of the mining operators.
\end{abstract}

\section{Introduction}

Modern mining companies operate in a complex business environment and are facing significant challenges and uncertainties related to technical, market, economic, financial, political, and other factors affecting their management and operations. In recent decades there has been a trend towards a rapid evolution of sustainability and the concept of sustainable development. Whereas traditionally mining operators considered sustainability as a compliance issue nowadays successful companies in this sector are becoming aware of

\footnotetext{
* Corresponding author: yuliia.lazarenko@,kneu.ua
} 
the business opportunities and competitive advantages related to sustainable products and services. This corresponds with the contemporary understanding of the specific nature of the mining industry according to which sustainable development that is aimed at finding a balance between achieving the benefits of the mining operations and the improving of the economic, social, and environmental sustainability, which results in the optimization of positive impacts is becoming a critical issue that should be taken into consideration in the development and implementation of the competitive strategy. In this vein, a competitive advantage can be achieved by identifying how sustainability can meet the value creation in the industry.

The issues associated with the sustainable development goals and sustainability in the mining sector have gained popularity over the past years, however, from a managerial perspective, a relationship between traditional competitive strategies and sustainability strategies requires further examination. This research focuses on defining a theoretical basis for a deeper understanding of the strategic management for sustainability in the mining sector, which is regarded as an integrative management approach and implies a systematic adoption of the initiatives related to the sustainability domains in order to create long-term values and achieve sustainability outcomes. The paper is intended to identify its significant elements as well as strategic areas for mining operators. Based on a conceptual review of the literature related to the strategic mine management for sustainability, key drivers and firm-level factors which should be primarily taken into account from a company's viewpoint to embed efficiently the sustainability strategies into the business practice of mining operators are pointed out in the paper.

\section{Materials and Methods}

Nowadays modern companies operate in a constantly changing business environment that features fewer resources, environmental challenges, increased social inequity, as well as more engaged stakeholders such as local communities and authorities, non-governmental and civil society organizations, as well as industrial unions, and increased focus on corporate transparency and social responsibility. Mining companies should understand how these shifts impact their business and find innovative solutions to societal along with ecological challenges while maintaining productivity, profitability, and financial performance.

Sustainability as a business approach to creating long-term value is becoming more important for all companies, across all sectors of industry. According to the information presented by International Institute for Management Development (IMD), 62\% of executives consider a sustainability strategy necessary to be competitive in the modern business environment, and another $22 \%$ hold the view this trend can be pursued in the future [1]. Sustainability as a broad concept implies responsible economic growth to achieve current goals while protecting natural resources for future generations [2]. But it cannot be considered exclusively from an environmental perspective. This paper uses a multidimensional approach to understanding sustainability in the mining sector which assumes that three key focus areas should be highlighted: environmental, economic, and sociocultural dimensions.

This paper presents a theoretical framework for investigating the relationship between the sustainable-oriented strategies and competitive advantages in the mining sector and strives to extend the existing literature by providing a basis for defining the key drivers and strategic areas of sustainable development at the firm level which are from a management perspective of critical importance for effective formulation and implementation of the sustainability strategy and its integration into the business operations of mining companies. The paper is structured as follows: first, a descriptive overview of the theoretical aspects of 
sustainable development in the mining sector is provided. Then, based on a review of the existing literature of strategic management for sustainability and thematic research, a definition of sustainable competitiveness of a company as a complex and multifaceted concept is proposed. As a result of the study, through the integrated approach to sustainability, a conceptual framework for strategic sustainability management of mining companies is presented and managerial applications are developed that can be used by mining operators to adopt, formulate and successfully implement action plans of corporate sustainability strategies.

\section{Results and Discussion}

Achieving a balance between corporate social and environmental responsibility and the identification of emerging market opportunities to increase profit margins provides the strategic tools necessary to gain a competitive advantage in the global business environment. It should be mentioned that in the mining sector sustainability is an important component of the corporate strategic planning process, implementation of appropriate strategic mechanisms related to sustainable development is intended to support strategic planning and may be an effective way to develop the competitive advantage of mining operators through innovative leadership while increasing their profit margins [3]. From a theoretical perspective, effective integrating long-term strategic priorities related to sustainable development into business practices of companies can be used as a basis for implementing a cost-leadership strategy that includes efficiency in every aspect of the planning procedures and operational activities [4]. With this regard, the sustainable business practices integrated into operation management strategies may yield benefits in terms of time and cost savings associated with using sustainable materials in the production process, which in turn, provide an opportunity to decrease operational costs and thus create the prerequisites for effective implementation of the cost reduction strategy that allows providing equivalent benefits to the customers, but at lower competitive prices.

In a competitive context, sustainable development can also be considered as one of the differentiating factors available to mining companies to build a competitive advantage within the industry in terms of consumers' environmental concerns, social programs, and the development of the local communities.

Recent studies have found that when a concept of sustainable development is integrated into a company's business strategy along with corporate activities that aim at developing a common sustainability awareness, it may result in benefits and competitive advantages, both in financial and non-financial dimensions, such as increased profitability, improved corporate reputation, as well as enhanced stakeholders involvement and customers' satisfaction $[5 ; 6]$. An image of being environmentally and socially responsible can enhance a company's reputation, create additional opportunities, as well as provide for a mining company a competitive advantage and access to potential resources. It can also lead to a more efficient operation process, integrated with the fundamental long-term interests of the local population. But even taking all benefits and advantages into account, some mining companies which operate on the global markets, view sustainability as a strategic challenge for their business. Furthermore, as the worldwide experience in this area had shown, mining operators are encountering difficulties in implementing sustainable development initiatives and corporate social responsibility practices on their own. There is a reasonable belief that such activities require partnerships between industry companies, local groups and regional governments to identify the needs and expectations, harmonize the complementary but often conflicting goals and interests of the various stakeholders, determine the best methods of maximizing benefits, and, as a consequence, deliver expected desirable results and outcomes for socially oriented and environmentally sustainable economic development. 
Extractive industries are nowadays confronted with serious challenges of sustainable development, in particular, with regard to environmental and social issues. The social pillar of sustainable development refers to, in broad terms, corporate mechanisms that support social issues related to the aspects like healthcare, education services, housing, employment, and other social needs. In this context mining operators can use a diverse range of possible activities to enhance positive social opportunities for individuals and communities which include grants and donations (direct support for healthcare, education services, or other social needs), training programs that are aimed at developing the skills and abilities of local people to participate in mining and related activities, employment that results in job creation with benefits for poverty reduction, as well as enhanced employment opportunities, both directly and with suppliers and contractors, capacity development in order to increase local business and support community-based initiatives for the local development, build and strengthen economic and managerial capacity to diversify the regional economy, as well as partnership relations to secure equity participation of the stakeholders in local mining projects $[7 ; 8]$. These types of social-oriented activities serve to highlight the attitude that a mining company can take towards a local community. The importance of working with stakeholders and establishing a good relationship with a local community and its people should be pointed out, in order to facilitate operations over the long term, improve risk management, enhance access to capital, and a company's reputation.

Numerous studies have examined the relationship between corporate social responsibility business practices and a firm's market and financial performance, with mixed empirical results, however, based on a literature review it can be concluded that most authors argue that a change of the organization activities towards raising awareness of the sustainable development goals will ultimately result in its long-term economic viability and competitive advantage $[9 ; 10]$. In this vein, the adoption of sustainable development practices is related not only to the enhanced strategic competitiveness of firms and industries but also contributes to the gaining and maintenance of competitive advantage in a sustainable way.

Although an exploring of key determinants and sources of strategic competitiveness of a company is an area of growing interest among both academics and practitioners, the current understanding of its essence in reference to sustainable development in the mining sector is still fragmented. This paper focuses on sustainable competitiveness at the organizational level, which refers to the company's operations, practices, and activities that are carried out in accordance with the principles of sustainable development, and can be defined as the ability of a business to respond to the customers' changing needs and market requirements more efficiently and effectively than competitors, while at the same time ensuring the value creation (the economic dimension), wellbeing generation (the social dimension), and environmental protection issues and maintaining natural ecosystems (the environmental dimension). Traditional mechanisms of achieving competitiveness in the mining sector are focused largely on the value generation and cost-reduction methods with regard to proper management and operational performance improvement. Sustainable competitiveness as the ability of firms to compete in markets, emphasizes the importance of cooperation and partnership with a wide range of stakeholders, sustainable quality management, customer orientation, building relationships with suppliers, efficient use of resources, investment in ecological solutions and "green projects", as well as developing competitive strategies in line with principles of corporate social responsibility $[11 ; 12]$.

Sustainability-oriented practices and corporate initiatives, as well as appropriate sustainability management systems, form a basis for the concept of sustainable competitiveness at the enterprise level. Thus, distinctive features of a sustainable competitive company include the ability to be competitive in the market, react to changes in 
market conditions and business requirements in a prompt, effective and flexible manner, while ensuring at the same time environmental and social responsibility to various groups of stakeholders by developing and implementing proactive sustainability strategies within the management system framework.

At the firm level, in order to support sustainability initiatives which positively contribute to business outcomes, it is necessary to translate sustainability strategy into tactical action plans and develop appropriate systems, structures, organizational goals, and performance indicators. In this view, we share the opinion that integrating sustainability strategy into the operational activities of a company should be considered as a managerial task that should take into consideration external and internal drivers, corporate values, leadership, company's reputation, market requirements, stakeholders' satisfaction, and other factors in order to change their business practices and provide successful implementation of the sustainability strategy that will help to reduce risks and uncertainties associated with environmental and social impacts and improve the benefits to be gained through sustainability-oriented initiatives.

With reference to the existing literature related to the driving factors of sustainable development and the implementation of sustainability concept into business models of mining operators, a conceptual generalized framework for strategic sustainability management of mining companies was established (Figure 1), that can be used by mining operators to adopt, formulate and successfully implement action plans of corporate sustainability strategies.

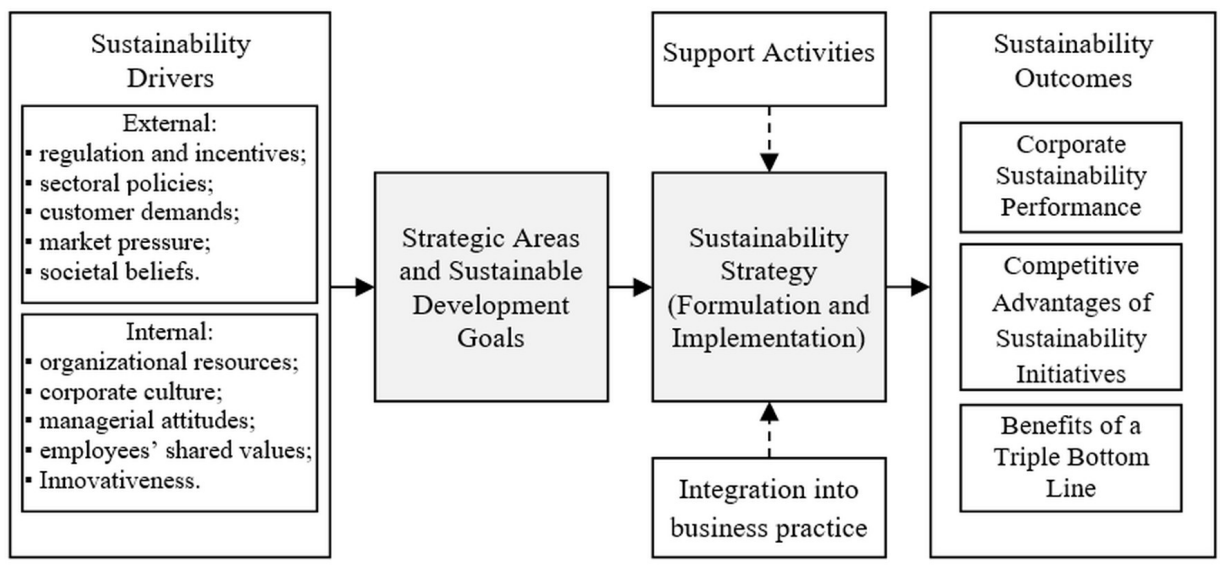

Fig. 1. A conceptual framework for strategic sustainability management of mining companies, source: Developed by authors adapting [13-17].

As indicated in Figure 1, when organizations develop sustainability-oriented strategies and integrate them into their corporate strategy and business practice, they may gain sustainability outcomes such as corporate sustainability performance, competitive advantages of sustainability initiatives, and benefits of a triple bottom line. With regard to sustainability drivers, mining companies are influenced by both internal and external factors that affect the adoption of specific sustainability initiatives. Among the major external drivers, the following should be mentioned: governments (sectoral policies, regulations, legislation and incentives, CSR action plans, and collaborative initiatives with businesses), market and societal pressure, customers' demands and stakeholders' expectations. In the context of the mining industry, international initiatives such as UNGC, SDSs, and GRI can be also highlighted as a driving factor for the company's sustainability business strategy [16]. Internal sustainability drivers include factors related to the 
organizational context that are supported by corporate culture and a company's business strategy, as well as by managerial attitudes and employees' shared values. By managing the internal drivers and integrating them into the sustainable business model, a company's sustainability strategy can be formulated, where apart from primary and supportive activities, the creation of sustainable competitive advantage should be at the core, along with appropriate plans, programs, management systems, and decision-making tools.

Business activities which are carried out in accordance with the sustainable development principles provide a comprehensive approach to improve the business survivability, reduce operating expenses, strengthen a company's corporate reputation and its investment attractiveness, build competitive advantages by optimizing the use of resources and the production processes and expanding collaboration with a wide range of relevant stakeholders. In the organizational context, key factors which determine business profitability with regard to sustainable development include innovation, environmental sustainability, and managers' commitment to optimizing the use of available resources, as well as internal operations using best practices, and continuous process improvement that should be aligned with corporate strategy and organizational objectives [18].

In the organizational context, the level of sustainable competitiveness of a company depends on numerous intra-firm factors, including sustainability vision, strategic management tools, knowledge management mechanisms, environmental strategies, such as pollution prevention strategy, clean technology strategy, and green strategy $[11 ; 19]$. In that regard, strategic management for sustainability aims at identifying internal and external drivers, and factors supporting sustainable development goals and implies systematic integration of the three sustainability domains (i.e., environmental, social, and economic dimension) in the operation activities of a company in order to create long-term values and sustainability outputs such as sustainable competitive advantage and a range of performance benefits. From a long-term perspective, integrating all three dimensions systematically and simultaneously will reshape business operations at all levels towards the achievement of sustainable development goals, provide a strategic competitive advantage, and help organizations manage risks and uncertainties in the environmental, social, and economic domains of the firm's operation [20].

\section{Conclusions}

The paper provides managerial implications that may be used by various stakeholders in the mining sector, such as mining operators and industry policy-makers. From a practical viewpoint, the presented framework can be conceptualized at the firm level as a business model which is oriented towards the achievement of competitive advantage, long-term values creation, and enhancing corporate sustainability performance of the mining operators. It could also serve as a basis for developing appropriate management tools for mining companies on how they can align their strategies with the realization of sustainable development goals. At the macro-level, external factors such as pressures from the global movements (e.g. climate change, "green" movement), and institutional policies in the mining sector can have great impacts on overall organizational strategies. In practice, it is recommended that business practitioners focus on revising their strategies in order to incorporate proposed sustainability-oriented practices in their systematic strategic planning. In terms of social issues, corporate responsibility should include activities that are integrated throughout a company and its business strategies. It also should be examined in relationship with corporate culture and business ethics rules which imply the integration of social, economic, and environmental factors in all the activities of a company.

Based on the findings of the study it can be concluded that for policy-makers this paper could present a strategic basis for development sustainability-oriented industry policy 
approaches. They can foster and support organizations which operate in accordance with the established principles of sustainability since they can be considered as the strategic drivers of sustainable development in the sector. The commitment to sustainable development and the integration of sustainability values and principles into the organization provides the mining operators an opportunity to respond to environmental concerns and social challenges in their respective local communities, to harmonize the interests and priorities of the company's stakeholders such as non-governmental and civil society organizations, industrial unions and environmental organizations, and therefore expand their competitive advantage which in turn will lead to improved performance and enhanced strategic competitiveness.

To summarize, in order to successfully establish and implement sustainability-oriented strategies the mining companies must be ahead of the policy, market, and societal pressures and reshape their business proactively in accordance with sustainable development goals. Appropriate solutions for mining enterprises' sustainability management are necessary to provide the optimized decision-making and put established theoretical frameworks of sustainability into business practices. Organizations should consider incorporating the proposed theoretical framework for sustainability management in their strategic planning system to provide the optimized decision-making and manage associated environmental, social, and economic opportunities and risks in business to achieve strategic sustainable competitiveness and resilience in the long run.

\section{References}

1. K. Haanaes. Why all businesses should embrace sustainability (IMD, International Institute for Management Development, Lausanne, 2016)

2. M.J. Epstein, Making sustainability work: Best practices in managing and measuring corporate social, environmental and economic impacts (Berrett-Koehler Publishers, San Francisco, 2008)

3. R.C. Padgett \& R.C. Moura-Leite, Journal of Technology Management \& Innovation, 7, 59 (2012)

4. E. Stankevičiūtè, R. Grunda, E.V. Bartkus, Economics \& Management, 17(3), 1200 (2012)

5. M.J. D'Angelo, J. Brunstein, International Journal of Sustainable Development \& World Ecology, 21(3), 273 (2014)

6. L. Escobar, H. Vredenburg, Journal of Business Ethics, 98(1), 39 (2011)

7. W. Dunn, CIM Bulletin, 93(1037), 41 (1999)

8. L.A. Lapalme, The Social Dimension of Sustainable Development and the Mining Industry: A Background Paper (Natural Resources Canada, Ontario, 2003)

9. N. Ortiz-de-Mandojana, P. Bansal, Strategic Management Journal, 37, 1615 (2016)

10. J. Van Kleef, N. Roome, Journal of Cleaner Production, 15(1), 38 (2007)

11. A. Karman, A. Savanevičienè, Baltic Journal of Management, 16(2), 318 (2020)

12. L. Bozikova, J. Snircova, Research Papers Faculty of Materials Science and Technology in Trnava Slovak University of Technology in Bratislava, 24(37), 15 (2016)

13. M.A. Saeed, W. Kersten, Sustainability, 11, 1137 (2019)

14. A. Melkonyan, D. Gottschalk, V.P. Vasanth Kamath, Sustainable Production and Consumption, 12(1) (2017) 
15. F. Kitsios, M. Kamariotou, M.A. Talias, Sustainability, 12, 521 (2020)

16. A. Ivic, N.M. Saviolidis, L. Johannsdottir, Sustainability, 2, 17 (2021)

17. M. Berns, A. Townend, Z. Khayat, B. Balagopal, M. Reeves, M.S. Hopkins, N. Kruschwitz, MIT Sloan Management Review, Sustainability and Competitive advantage, 51, 56 (2009)

18. J. Bouglet, O. Joffre, E. Simon, Society and Business Review, 7(3), 212 (2012)

19. M.A. Sellitto, F.F. Hermann, Engineering Management Journal: Special Issue from International Conference on Production Research, 31(2), 98 (2019)

20. S. Suriyankietkaew, P.A. Petison, Sustainability, 12(1), 91 (2020) 